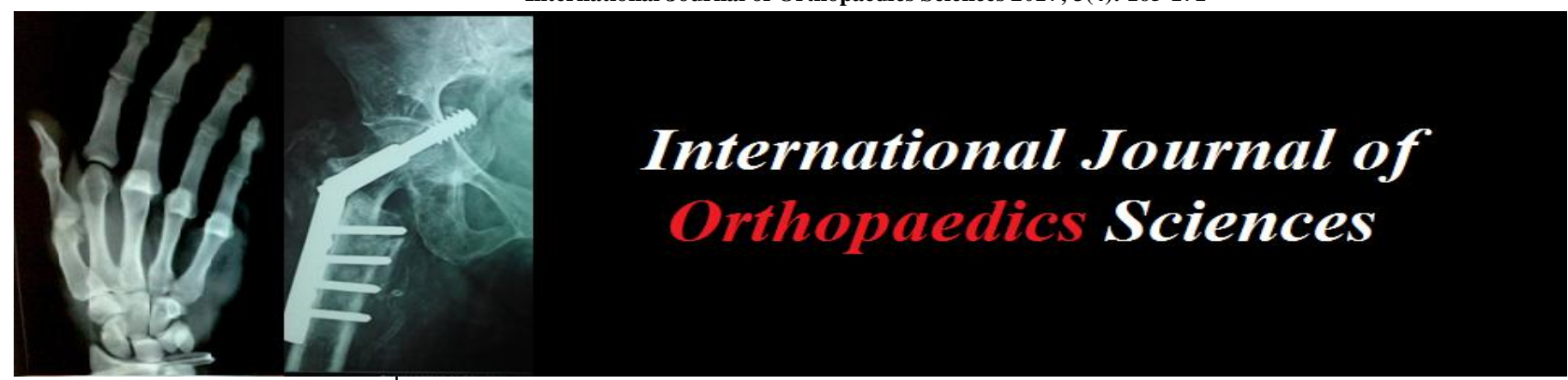

ISSN: $2395-1958$

IJOS 2017; 3(4): 165-171

(C) 2017 IJOS

www.orthopaper.com

Received: 24-08-2017

Accepted: 25-09-2017

Dr. Agni Raj R

Assistant Professor,

Department of Orthopedics,

Government Stanley Medical

College, Tamil Nadu, India

Dr. Tholgapiyan T

Professor, Department of Orthopedics, Government Stanley Medical College,

Tamil Nadu, India

Dr. Kathir Azhagan S Resident Department of Orthopedics, Government Stanley Medical College,

Tamil Nadu, India
Correspondence

Dr. Tholgapiyan T

Professor, Department of Orthopedics, Government Stanley Medical College,

Tamil Nadu, India

\section{Comparative analysis of the functional outcome of arthroscopic anterior cruciate ligament reconstruction using quadrupled hamstring graft fixed with bio absorbable interference screw against titanium interference screw}

\author{
Dr. Agni Raj R, Dr. Tholgapiyan T and Dr. Kathir Azhagan S \\ DOI: https://doi.org/10.22271/ortho.2017.v3.i4c.24
}

\begin{abstract}
Anterior cruciate ligament injury is one of the most common injuries around knee and poses quiet a lot management controversies. Anterior cruciate ligament has a pivot role in function and stability of the knee joint along with all other ligaments, being a prime stabilizer preventing the anterior translation of tibia over femur. Acute anterior cruciate ligament injury causes recurrent episodes of instability, pain and decreased motion. Anterior cruciate ligament reconstruction allows return to pre injury levels even in athletes, delays development of early osteoarthritis and reestablish the stability of the joint. Graft fixation during ACL reconstruction can be achieved with use of either metal screws or bio absorbable screws. Bio absorbable screws usage provide better visibility in postoperative MRI and also avoid removal at later stage. However there are controversies regarding the ideal graft, ideal fixation device, ideal time and technique of reconstruction. In this study we have compared the metal and bio absorbable screw for fixing the graft and reported the result.
\end{abstract}

Keywords: Anterior cruciate ligament reconstruction, bio absorbable interference screw, titanium interference screw

\section{Introduction}

The high number of ACL injuries is a growing problem with serious consequences for the patient and society. An acute ACL injury is seldom isolated (15\%), and is usually associated with concomitant injuries to the menisci $(60 \%)$, cartilage $(20 \%)$ and collateral ligaments.

Though Arthroscopic intra articular reconstruction has become gold standard in ACL reconstruction in this century there is still debate regarding the choice of graft, fixation methods, single or double bundle and trans portal or trans tibial technique.

More recent studies have proved quadrupled Hamstring is superior in strength ${ }^{[14]}$ but time for healing, probable loss of strength during healing and minimal hamstring weakness post operatively are considerations.

Recent studies have proved endobutton and bone mulch screw have a very high yield load than any other fixation device in view of soft tissue graft fixation ${ }^{[16]}$. The trans portal technique has been widely used nowadays but the trans tibial technique is easily reproducible and gives comparable functional outcomes though tunnel placement is not more accurate in trans tibial technique ${ }^{[17]}$.

Bio absorbable implants in orthopaedic surgery was introduced by Rokkanan et al and bostman et al for use in surgery of the ankle ${ }^{[18]}$. In 1987, Kurosaka introduced the current concepts of interference screw fixation ${ }^{[19]}$.

Aim

To do comparative analysis of the functional outcome of Arthroscopic Anterior Cruciate Ligament Reconstruction using quadrupled hamstring graft with endobutton as femoral fixation device and bio absorbable interference screw against titanium interference screw as tibial fixation devices respectively. 
Materials and Methods

The Retrospective and prospective study of 60 patients treated with arthroscopic anterior cruciate ligament reconstruction with quadrupled hamstring graft with endobutton as the femoral fixation device and titanium interference screw $($ no $=30)$ and bio absorbable interference screw $($ no=30) as tibial fixation device respectively between May 2012 and November 2013 at institute of orthopaedics and traumatology, Rajiv Gandhi government general hospital, Chennai

\section{Inclusion Criteria}

- Patients with closed growth plate

- Primary ACL surgery

- No evidence of multiple ligament injury

- No previous knee surgeries

- No ligamentous injury to contralateral knee

\section{Exclusion Criteria}

- Additional ligamentous laxity in affected knee

- Previous ACL surgery of either knee

- Chronic muscle disorders

- Any co-existing local conditions in the form of -Active articular infection -Inflammatory joint disease

- Metabolic bone disease

- Neoplastic disease

\section{Evaluation}

All the patients are subjected for post-operative antero posterior and lateral radiographs to determine the tunnel placement and position of endobutton in femur and interference screw in the tibia. Patients are followed at 4 weeks, 8 weeks, 3 months, 6 months and once in 6 months thereafter.

All patients are evaluated with Lysholm \& Gillquist scoring.

\section{Knee Scoring Scale of Lysholm \& Gillquist \\ Limp}

None

Slight /periodic or both

Constant or severe or both

\section{Support}

None

Cane or crutch

Weight bearing impossible

\section{Locking}

No locking or catching sensations

Catching, but no locking sensations

Locking - occasionally

Locking - Frequently

Locked on examination

\section{Instability / Giving Way}

Never

Rarely during athletic activity or any other heavy exertion 20

Frequently during athletics or any other heavy exertion $\quad 15$

Rarely in daily activities 10

Frequently in daily activities

At every step

\section{Pain}

None

Inconstant or slight during heavy exertion

Marked during heavy exertion

Slight during a walk $>2 \mathrm{~km}$
Marked during a walk $<2 \mathrm{~km}$

\section{Swelling}

None

Mild on exertion

Marked on exertion

Constant

\section{Stair Climbing}

No problems

Slightly impaired

One step at a time

Impossible

\section{Squatting}

No problems

Slightly impaired

Knee flexion possible only up to 90 degrees Impossible

\section{Statistical Analysis}

Data reported as mean and significant difference between the two groups was studied using Yate's corrected Chi-Square test.

\section{Observation and Results}

60 Cases of arthroscopy assisted Anterior cruciate ligament reconstruction with quadrupled hamstring tendon graft using endobutton as the femoral fixation device and titanium interference screw $(\mathrm{no}=30)$ and bio absorbable interference screw $(n o=30)$ as tibial fixation device respectively was followed for 6 months to 1.5 years. The mean follow up was 10.5 months

\section{Age Distribution}

Minimum age was 20 years and maximum age was 55 with a mean age of 31.6 (Table 1 and Chart 1)

Table 1: Age distribution

\begin{tabular}{|c|c|c|}
\hline Age & Patients & Percentage \\
\hline $15-20$ & 3 & 5 \\
\hline $21-25$ & 16 & 26.66 \\
\hline $26-30$ & 14 & 23.33 \\
\hline $31-35$ & 11 & 18.33 \\
\hline $36-40$ & 6 & 10 \\
\hline $41-45$ & 7 & 11.66 \\
\hline $46-50$ & 2 & 3.33 \\
\hline $51-55$ & 1 & 1.66 \\
\hline Total & 60 & 100 \\
\hline
\end{tabular}

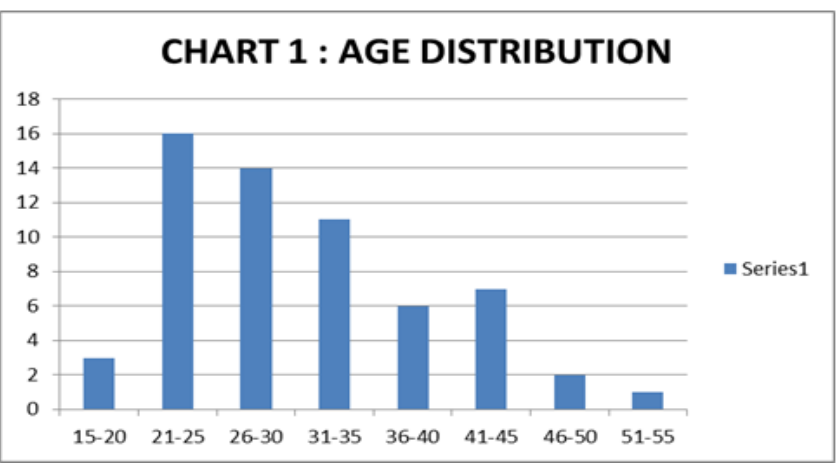

\section{Sex Distribution}

In this study, 51 patients were males and 9 patients were females (table 2 and chart 2) 
Table 2: Sex distribution

\begin{tabular}{|c|c|c|}
\hline Sex & Patients & Percentage \\
\hline Male & 51 & 85 \\
\hline Female & 9 & 15 \\
\hline Total & 60 & 100 \\
\hline
\end{tabular}

\section{CHART 2 : SEX DISTRIBUTION}

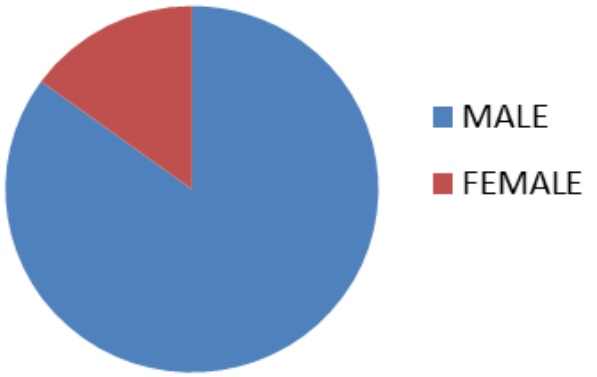

Side Involved

In this study, 40 patients had injury in the right knee and 20 patients had injury in the left knee (Table 3 and Chart 3 )

Table 3: Side involved

\begin{tabular}{|l|l|l|}
\hline Side involved & Patients & Percentage \\
\hline Right & 40 & 66.66 \\
\hline Left & 20 & 33.33 \\
\hline Total & 60 & 100 \\
\hline
\end{tabular}

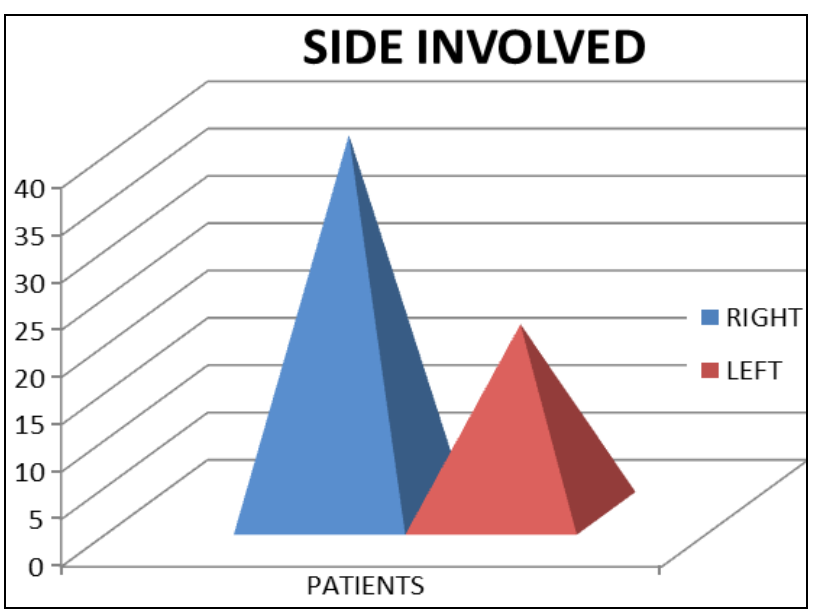

Mode of Injury

\begin{tabular}{|c|c|c|}
\hline Mode of injury & Patients & Percentage \\
\hline SPORTS & 10 & 16.6 \\
\hline FALL & 22 & 36.66 \\
\hline RTA & 28 & 46.66 \\
\hline TOTAL & 60 & 100 \\
\hline
\end{tabular}

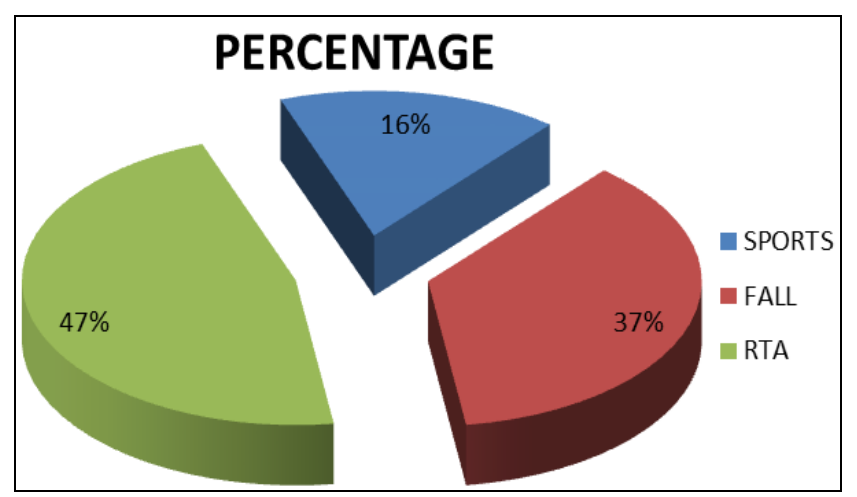

Duration of Injury

\begin{tabular}{|c|c|c|}
\hline Duration after injury & Patients & Percentage \\
\hline$<6$ WEEKS & 12 & 20 \\
\hline 6-3 MONTHS & 10 & 17 \\
\hline 3-6 MONTHS & 14 & 23 \\
\hline 6-12 MONTHS & 14 & 23 \\
\hline$>12$ MONTHS & 10 & 17 \\
\hline TOTAL & 60 & 100 \\
\hline
\end{tabular}

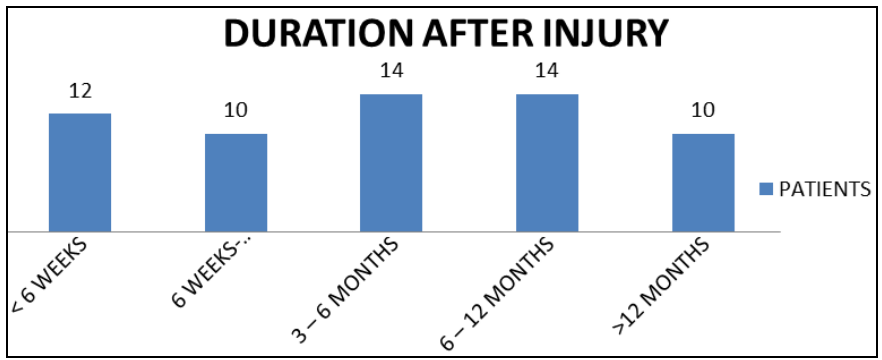

\section{Associated Injury}

\begin{tabular}{|c|c|c|}
\hline Associated injury & Patients & Percentage \\
\hline Medial meniscus tear & 13 & 22 \\
\hline Lateral meniscus tear & 3 & 5 \\
\hline Both & 2 & 3 \\
\hline Nil & 42 & 70 \\
\hline Total & 60 & 100 \\
\hline
\end{tabular}

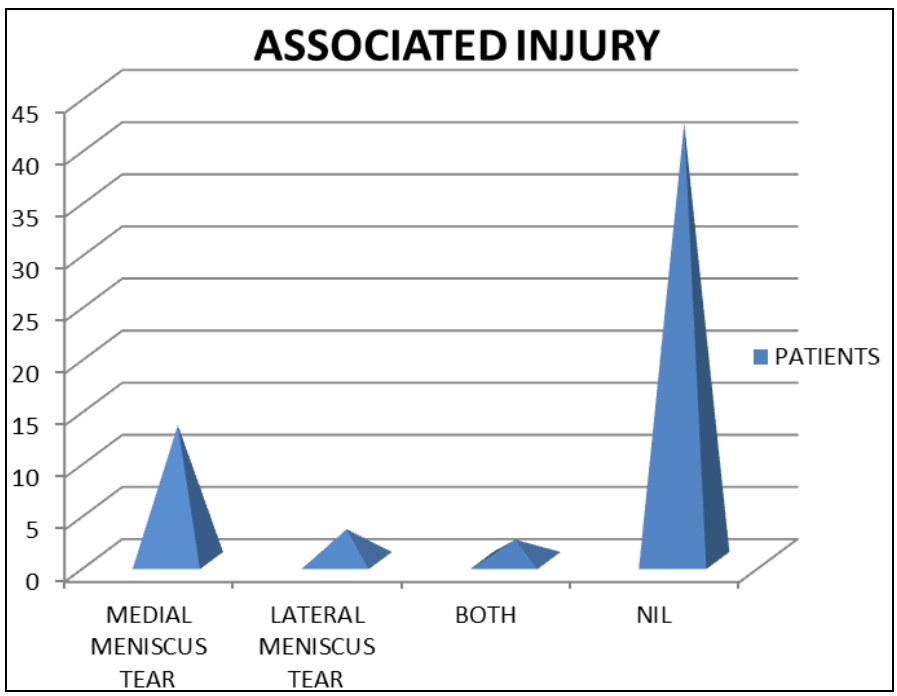

\section{Observation}

- Greater number of our patients was seen in the younger age group of 20-40 years.

- Male preponderance was noticed in our study

- Right side was involved more commonly than left side

- Road traffic accident was the most common cause accounting for ACL injury.

- Medial meniscus injury was involved more than the lateral meniscus.

- Most of the patients returned to their pre-functional level at 4 months.

\section{Scoring Analysis}

60 patients of arthroscopic acl reconstruction with quadrupled hamstring graft was followed for a minimum period of 6 months and maximum period of 1.5 years. All patients are evaluated with Lysholm and Gillquist scoring at the end of 6 months. The maximum score achieved was 100 and minimum score was 56.The scores were graded as 


$\begin{array}{ll}\text { Outcome } & \text { Points } \\ \text { Good } & 84-100 \\ \text { Fair } & 65-84 \\ \text { Poor } & <65\end{array}$

Two patients in titanium interference group and one patient in bio absorbable interference screw group lost to followup.

\begin{tabular}{|c|c|c|c|c|}
\hline Outcome & Titanium screw gp.no of patients (28) & Percentage & Bio-abs screw gp. No of patients (29) & Percentage \\
\hline Good & 23 & 82.14 & 24 & 82.75 \\
\hline Fair & 3 & 10.71 & 3 & 10.34 \\
\hline Poor & 2 & 7.14 & 2 & 6.89 \\
\hline
\end{tabular}

By Yates corrected Chi-Square Test,

$\mathrm{X}^{2}=0.06 \mathrm{P}=0.97$

The clinical outcome was nearly equal in both the groups.

\section{Good Results}

In our study 23 patients in titanium interference screw group and 24 patients in bio absorbable interference group had good results and the patients had no limp, were able to walk without support, there was no locking except for a few with mild instability during athletics or heavy exertion. There was no pain or swelling of the knee joints. There was no difficulty in climbing stairs or squatting.

\section{Fair Results}

In both the groups, 3 patients had fair results with the following clinical findings. There was slight limping, occasional locking, with mild instability during daily activities. There was anterior pain and swelling on exertion. squatting and stair climbing were slightly impaired.

\section{Poor Results}

In both the groups, 2 patients had poor results, with painful weight bearing. The patient walked with support, and felt the knee giving way in daily activities. There was constant swelling and pain of anterior knee joint. Squatting and climbing stairs was painful.

The above 4 patients with poor results had lachmans and anterior drawer test positive with restricted knee movements. These may be due to improper graft tension and in cooperation during postoperative rehabilitation. 2 of the 4 patients had infection and septic arthritis 10 days following which subsided with arthrotomy and joint lavage and
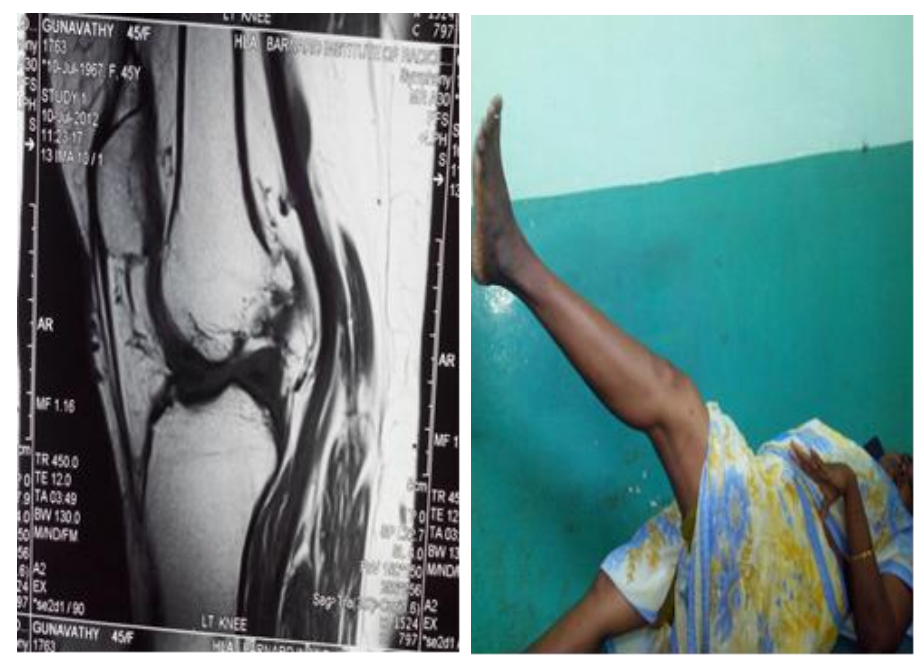

Case Serial No-2

Name: Mr. Srinivasan

Occupation

Age: 38

Sex: Male

Duration between Injury \& Surgery

Date of Admission

Mode of Trauma

Side Involved antibiotics.

\section{Complications}

One patient had post-operative infection and patient presented on $10^{\text {th }}$ post-operative day with fever, pain and inability to move the limb. Septic arthritis was suspected and patient treated with open arthrotomy and joint debridement and antibiotics for 4 weeks and infection subsided.

The most common intraoperative complication proposed for bio absorbable interference screw were screw breakage, graft injury and aseptic effusion or synovitis of knee joint, but we did not encounter such problems in our study.

\section{Case Illustrations}

\section{Case Serial No-1}

Name: Mrs. Gunavathy Age: $45 \quad$ Sex: Female

Occupation : House wife

Duration between Injury \& Surgery: 8 months

Date of Admission : 07.01.13

Mode of Trauma : RTA

Side Involved : : Left Side

Associated Injuries

Systemic Illness

Type of Anaesthesia

Complication

Lysholm gillquist score

Post op follow up

Screw used

: Lateral meniscus tear

: Nil

: Spinal

: Nil

$: 95$

: 11 months

: Titanium interference screw
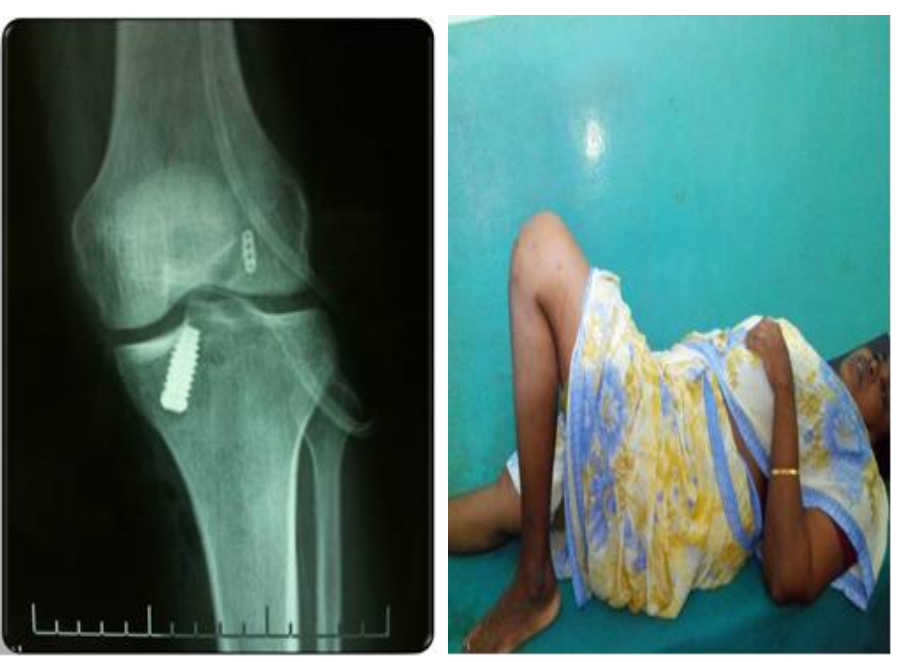

Associated Injuries $\quad$ : Nil

Systemic Illness : Nil

Type of Anaesthesia : : Spinal

Complication : Nil

Lysholm Gillquist score : : 92

Post op follow up : 6 months

Screw used : : Bio absorbable interference screw 

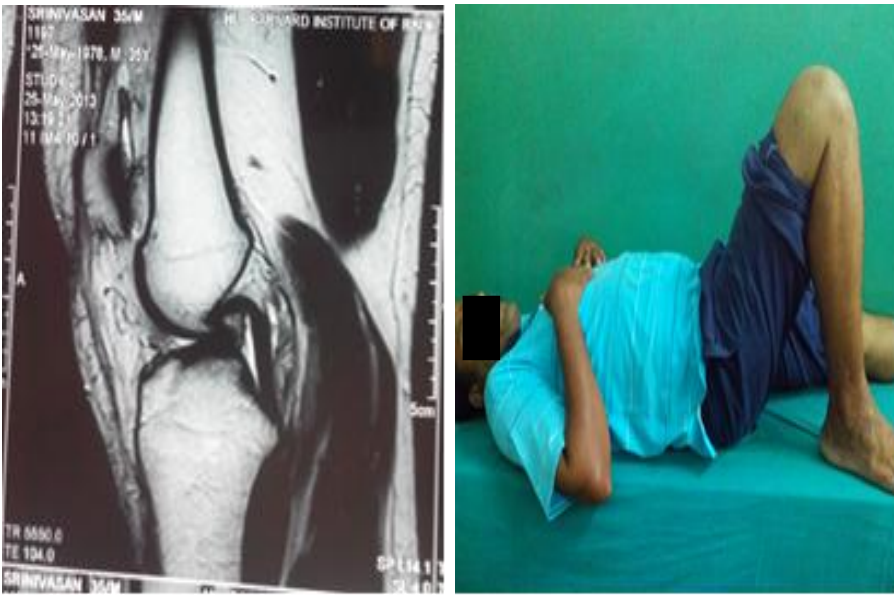

\section{Discussion}

Our study is to evaluate the functional outcome of arthroscopic single bundle ACL reconstruction with quadrupled Hamstring graft with transtibial and transportal techniques using endobutton as femoral fixation device and titanium interference screw in 30 patients and bio absorbable interference screw in 30 patients as tibial fixation device.

In our study fall and road traffic accidents predominated as the cause of injury accounting for $37 \%$ and $47 \%$ respectively. Sports injuries accounted for only $10 \%$ in contrary to all international studies. D W Lewis reported 58\% meniscal injury associated ACL tear at presentation. Medial meniscus was involved more than the lateral meniscus in his study and he also proposed meniscal repair or resection did not alter the outcome and chondral lesions are a better predictor of funtional outcome. Stephen Lyman reported more than $50 \%$ meniscal procedures with ACL reconstructions in 2009.In our study $30 \%$ of patients had meniscal injury at presentation and medial meniscus injury predominated lateral meniscus injury like other studies. None of our patients had significant chondral damage at diagnostic arthroscopy.

The fixation of the graft has been proved to be the site of failure rather than the graft itself irrespective of the type of graft especially in the early rehabilitation phase when the graft integration has not taken place and the fixation is of little significance after 8 to 12 weeks when graft has integrated with the bone as proposed by Dawn T Gulick ${ }^{[41]}$.

In our study we used transtibial or transportal single bundle reconstruction with quadrupled hamstring graft placing the femoral tunnel between 1030 and 11'o clock position in the right knee and between 1'o clock and 130 position in the left knee. John Paul [47] proposed that placing graft at 1030 position and 130 position in single bundle reconstruction reconstructs portions of anteromedial and posterolateral bundles. Masayoshi Yagi [48] showed that anatomic reconstruction allowed better rotatory stability than nonanatomic placements of graft. Asheesh Bedi [49] showed that trans portal placement of tunnel achieved more lateral placement than the trans tibial drilling and trans tibial approach to achieve lateral tunnel placements resulted in over reaming of tibia. Though double bundle reconstructions have gained attraction and studies have shown double bundle reconstruction to be superior in providing stability in high demand patients. Adachi, Ochi and Uchio ${ }^{[50]}$ showed no significant advantage of double bundle reconstruction than anatomic single bundle reconstruction in factors of stability and proprioception in general population.

The metallic screws distort the knee MRI wherein bio absorbable screw avoids impairment of imaging. Apart from
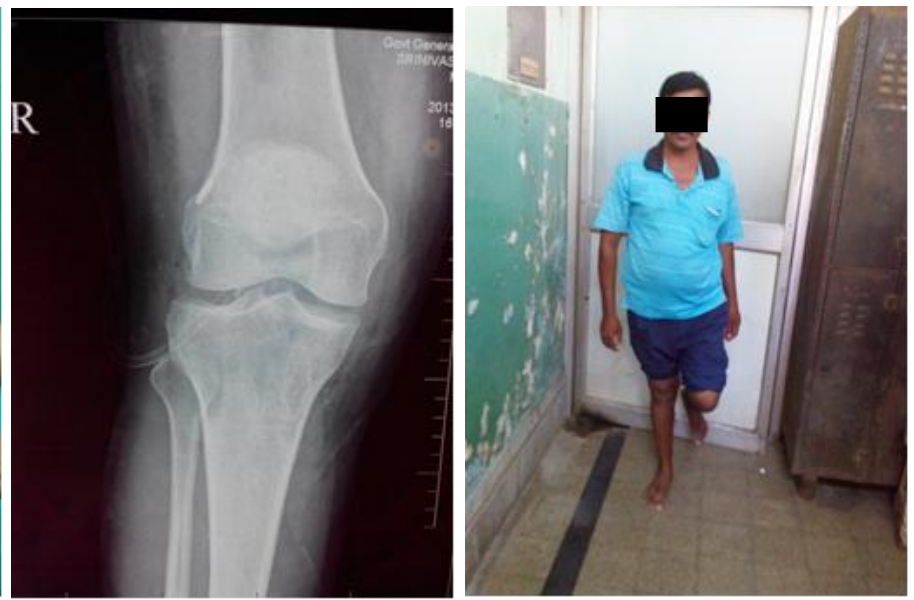

this metallic screws have to be removed during surgical revision wherein bio absorbable screws would have been degraded. The major disadvantages are screw breakage at the time of insertion and postoperative inflammatory reaction causing synovitis. We did not come across such problems in our study.

In our study, functional outcome evaluated by Lysholm and Gillquist scoring was nearly equal in both titanium interference screw study group and bio absorbable interference screw study group and it is statistically insignificiant with $\mathrm{P}$ value of 0.97 . Our study shows that there is no significant difference in the outcomes associated with the use of titanium and bio absorbable interference screws used for anterior cruciate ligament reconstruction.

Since our study was a short term follow up we could not comment about the arthritic changes post operatively. Fox et al ${ }^{[51]}$ reported 3 to $17 \%$ incidence of anterior knee pain, compared to $13 \%$ in our study, Apostolopoulos ${ }^{[52]}$ reported $10 \%$ of anterior knee pain. Kurt Spindler ${ }^{(53)}$ stated regular exercise can lead to increased outcomes in 2005. Our patients are put on home based physiotheraphy programe insisting on knee flexion and quadriceps strengthening and mean flexion achieved was 135 degree.J A Grant ${ }^{[54]}$ concluded that home based physiotheraphy is cost effective and not significantly inferior to supervised programmes. As overall conclusion several factors influence the functional outcome in arthroscopic ACL reconstruction. Factors like graft choice, graft fixation, tunnel placement and graft tensioning play a vital role in altering the final outcomes.

\section{Conclusion}

The results of our study were comparable with already published reports of comparative study done using bio absorsable versus metal interference screws. Our study shows that there is no difference in functional outcome whether bio absorbable or titanium interference screw was used.

The success of ACL reconstruction depend on the correct technique used for the surgery, precise placement of graft and rehabilitation methods than on type of graft fixation device used, neither titanium nor bio absorbable screws.

The blunt metal or titanium screw has been the de facto standard in graft fixation. Since the alternate bio absorbable screw overcomes some of the potential drawbacks, it should become the de facto standard in the future.

\section{References}

1. Butler DL, Noyes FR, Grood ES. Ligamentous restraints to anterior- posterior drawer in human knee. A biomechanical study. J Bone Joint Surg Am 1980; 62:25970 . 
2. Haimes JL, Wroble RR, Grood ES, Noyes FR - Role of medial struc-tures in the intact and anterior cruciate ligament deficient knee. Limits of motion in the human knee. Am J Sports Med. 1994; 22:402-409.

3. Satku K, Kumar VP, Ngoi SS. ACL injuries. To counsel or to oper-ate? J Bone Joint Surg Br 1986; 68:458-61

4. Howe, Johnson, Kaplan. ACL reconstruction using quadriceps patellar tendon graft. Part I. Long term follow up. Am J of Sports Med 1991; 19:447-57.

5. $\mathrm{Fu} \mathrm{FH}$, Bennett $\mathrm{CH}, \mathrm{Ma} \mathrm{CB}$. Current trends in anterior cruciate ligament reconstruction: Operative procedures and clinical correlation. Am J of Sports Med. 2000; 28:124-130.

6. Galen C. On the usefulness of the parts of the body. Ithaca Cotnett Univer, 100.

7. Bonnet A. Traite Des Maladies Articulaires -2nd edition: Baillire, Paris.pp 1853; 354-357.

8. Segond PF. Recherches cliniques et experimentales sur les epanchements sanguins du genou par entorse. Prog med 1879; 16: 297-421.

9. Alwynsmit. Anatomy, biomechanics, diagnosis and treatment clinical ortho - page 172 - 180. Alexander A sapoga anatomical and biomechanical consideration. JBJS. 1983, 1990, 250.

10. Kurosaka M, Yoshiya S, Andrish JT. Abiomechanical comparison of different surgical techniques of graft fixation in anterior cruciate ligament reconstruction Am. J Sports Med. 1987; 15:225-229.

11. Friedman MJ. Arthroscopic semitendinosus (gracilis) reconstruction for anterior cruciate ligament deficiency. Techniques in Orthopaedics. 1988; 2:74-80.

12. Rosenberg TD. Technique for endoscopic rnethod of ACL reconstruction Technical Bulletin. Mansfield. MA. Acufex Microsurgical, 1993.

13. Shelbourne, Wilckeus. Arthrofibrosis in acute anterior cruci ate ligament reconstruction. Am J of Sports Med 1991; 19:332-336.

14. Dyson L, Hamner MD. Hamstring Tendon Grafts for Reconstruction of the Anterior Cruciate Ligament: Biomechanical Evaluation of the Use of Multiple Strands and Tensioning Techniques. The Journal of Bone and Joint Surgery, Incorporated. 1999; 81(4).

15. Rubeinstein R, Shelbourne KD, Vanmeter CD. Isolated autogenous bone patellat tendon bone graft site morbidity : Am J sports Med $1994 ; 22: 324-327$

16. Petteri Kousa MD, Teppo LN, Järvinen MD, PhD The Fixation Strength of Six Hamstring Tendon Graft Fixation Devices in Anterior Cruciate Ligament Reconstruction

17. The American Journal of Sports Medicine. 2003; 31(2) American Orthopaedic Society for Sports Medicine.

18. Rokkanen P, Bostman O, Vainionpaa S, Vihtonen K, Tormala $\mathrm{P}$, Laiho $\mathrm{J}$ et al. Biodegradable implants in fracture fixation: early results of treatment of fractures of the ankle. Lancet. 1985; 1(8443):1422-1424.

19. Abe S, Kurosaka M, Iguchi T, Yoshiya S, Hirohata K. Light and electron microscopic study of remodelling and maturation process in autogenous graft for anterior cruciate ligament reconstruction. Arthroscopy. 1993; 9(4):394-405.

20. Lieutenant Commander John-Paul H. Rue, MD, Paul B. Lewis, MD, MS, A. Dushi Parameswaran, MD, and Bernard R. Bach Jr., MDSingle-Bundle Anterior Cruciate Ligament Reconstruction: Technique Overview and Comprehensive Review of Results The Journal Of Bone \& Joint Surgery · Jbjs.Org Volume 90-A · Supplement,
2008.

21. Ellison AE, Berg EE. Embryology, anatomy and function of the anterior cruciate ligament. Orthop Clin NA 1985; 16:3-14.

22. Girgis FG, Marshall JL, Monajem ARSA. The cru-ciate ligaments of the knee joint. Anatomical functional and exper-imental analysis. Clin Orthp 1975; 106:210-31.

23. Strocchi R, DePasquale V, Gubellini P, The human anterior cruciate ligament: histological and ultra structural observations. J Anat 1992; 180:515-519.

24. Arnoczky SP, Anatomy of the anterior cruci-ate ligament. Clin Orthop. 1983; 172:19-25.

25. Reiman PR, Jackson DW. Anatomy of the anterior cruciate ligament. In: Jackson DW, Drez D, editors. The anterior cruciate ligament deficient knee. St. Louis: CV Mosby \& Co: 1987; 17-26.

26. Matsumoto H, Suda Y, Otani T. Roles of the anterior cruciate ligament and the medial collateral ligament in pre-venting valgus instability. J Orthop Sci. 2001; 6:2832.

27. Woo SL, Hollis M, Adams DJ. Tensile proper-ties of the human femur - anterior cruciate ligament - tibia complex. The effects of specimen age and orientation. Am J of Sports Med. 1991; 19:217-25.

28. Freddie $\mathrm{H}$. Fu Christopher D. Biomechanics of knee ligaments. JBJS. 1993; 74:1716.

29. Canale \& Beaty: Campbell's Operative Orthopaedics, 11th ed Slocum DB, Larson RL. Rotatory instability of the knee, its pathogenesis and a clinical sign to demonstrate its presence. J Bone Joint Surg. 1968; 50-A:211-225.

30. Satku K, Kumar VP, Ngoi SS. Anterior cruciate ligament injuries. To counsel or to operate? J Bone Joint Surg. Br. 1986; 68-458-61.

31. Torg JS. Conrad W, Kalen V. Clinical diagnosis of anterior cruciate ligament instability in the athlete. Am J Sports Med. 1976; 4:84-91

32. Galway RD, Beaupre A, Macintosh DL - Pivot shift: a clinical sign of symptomatic anterior cruciate insufficiency. J Bone Join Surg. (Br). 1972; 54B:763-764.

33. Fiseher SP. Accuracy of diagnosis from MRI knee JBJS. 1991; 73:(2-9).

34. Rubinstein RAJ, Shelbourne KD. Graft selection, placement, fixation and tensioning for Anterior cruciate ligament reconstruction. Operative Tech Sports Med. $1993 ; 1: 10-15$.

35. Lewis DW, Chan D, Fisher O, Lechford R, Mintowt-Czyz WJ. Incidence Of Meniscal And Chondral Injuries At The Time Of Acl Reconstruction, And Their Relationship With Outcome At 2 Years. J Bone Joint Surg. 2012; 94:IX-41.

36. Harvey A, MBBS, FRCS (Tr \& Orth), N. P. Thomas, BSc, FRCS (Hons), Fixation of the graft in reconstruction of the anterior cruciate ligament 10.1302/0301620X.87B5.15803J Bone Joint Surg Br May 2005; 87 (5):593-603.

37. Arne Aune K. MD, PhD, Inger Holm PT, PhD, May Arna Risberg, PT, PhD, Hanne Krogstad Jensen, PT, and Harald Steen, MD, PhD Four-Strand Hamstring Tendon Auto graft Compared with Patellar Tendon-Bone Auto graft for Anterior Cruciate Ligament Reconstruction A Randomized Study with Two-Year Follow-Up THE American Journal Of Sports Medicine. 2001; 29(6). American Orthopaedic Society for Sports Medicine.

38. Michael Wagner, MD, Max J. Kääb, MD, PhD, Jessica Schallock, Norbert P. Haas, MD, PhD Hamstring Tendon 
Versus Patellar Tendon Anterior Cruciate Ligament.

39. Reconstruction Using Biodegradable Interference Fit Fixation A Prospective Matched-Group Analysis Am J Sports Med 2005; 33:1327

DOI: $10.1177 / 0363546504273488$

40. David Greenberg MD, Michael Robertson MD, Santaram Vallurupalli MD, Richard A, White MD, William C. Allen, MD Allograft Compared with Autograft Infection Rates in Primary Anterior Cruciate Ligament Reconstruction. J Bone Joint Surg Am. 2010; 92:2402-8. d doi:10.2106/JBJS.I.00456

41. Thomas D Rosenberg Extensor Mechanism after Patellar Tendon Harvest in Acl Reconstruction Ajsm. 1992; 20(5).

42. Dawn T. Gulick Anterior Cruciate Ligament Reconstruction: Clinical Outcomes of Patella Tendon and Hamstring Tendon Grafts Journal of Sports Science and Medicine. 2002; 1:63-71.

43. Steiner ME, Hecker AT, Brown CH Jr, Hayes WC. Anterior cruciate ligament graft fixation: comparison of hamstring and patellar tendon grafts. Am j sports Med 1994; 22:240-6.

44. Petteri Kousa MD, Teppo L. N. Järvinen, $† \S \mathrm{MD}, \mathrm{PhD}$, Mika Vihavainen, $\dagger$ Pekka Kannus, $\dagger_{-} \mathrm{MD}, \mathrm{PhD}$, and Markku Ja“ rvinen, $\dagger$ MD, PhD The Fixation Strength of Six Hamstring Tendon Graft Fixation Devices in Anterior Cruciate Ligament Reconstruction The American Journal Of Sports Medicine. American Orthopaedic Society for Sports Medicine, 2003.

45. Robert G. Marx, M.D., M.Sc., F.R.C.S.C., and Christopher R. Spock, B.A. Complications Following Hamstring Anterior Cruciate Ligament Reconstruction With Femoral Cross-Pin Fixation Arthroscopy: The Journal of Arthroscopic and Related Surgery. 2005; 21(6):762.e1-762.e3.

46. Chae-Gwan Kong, MD1, Yong In, MD2, Geon-Hyeong Kim, MD1 Cross Pins versus Endobutton Femoral Fixation in Hamstring Anterior Cruciate Ligament Reconstruction: Minimum 4-Year Follow-Up Knee Surg Relat Res. 2012; 24(1):34-39.

47. A Cadaveric Study Relating Transtibial Lateralized Femoral Tunnel Position to the Anteromedial and Posterolateral Bundle Femoral Origins of the Anterior Cruciate Ligament Biomechanical Analysis of an Anatomic Anterior Cruciate Ligament Reconstruction Masayoshi Yagi, Eric K. Wong, Akihiro Kanamori, Richard E. Debski, Freddie H. Fu and Savio L-Y. Woo Am J Sports Med 2002; 30:660.

48. Asheesh Bedi MD, Volker Musahl MD. Volker Steuber MD. Transtibial Versus Anteromedial Portal Reaming in Anterior Cruciate Ligament Reconstruction: An Anatomic and Biomechanical Evaluation of Surgical Technique Arthroscopy: The Journal of Arthroscopic and Related Surgery. 2011; 27(3):380-390.

49. Adachi N, Ochi M, Uchio Y, Iwasa J, Kuriwaka MY. Ito Reconstruction of the anterior cruciate ligament SINGLEVersus Double-Bundle Multi-stranded hamstring Tendons. J Bone Joint Surg [Br]. 2004; 86:515-20. Received, 2003. 